\title{
Assessment of the Organization and Management of Functional Adult Literacy Program in Some Selected Woredas of West Harerghe Zone of Oromia
}

\author{
Ayele Kumsa* \\ Madda Walabu University, College of Education and Behavioral Studies, Department of Adult Education and \\ Community Development, Bale Robe, Ethiopia \\ Fekadu Dechassa \\ Madda Walabu University, College of Education and Behavioral Studies, Department of Educational planning \\ and Management, Bale Robe , Ethiopia
}

\begin{abstract}
Although Functional Adult literacy Program is started in Ethiopia, its management and Organization system has not been developed as per government strategies. It needs serious attentions from the grass root level. As a result, the study was intended to assessing the Organization and Management of Functional Adult Literacy Program. To achieve this objective, descriptive survey method was used. Data gathered using questionnaires, interviews, observation and document review. The participants were trainees, facilitators and Adult Education Technical Committee.Out of $121(55 \%)$ trainees, (78(52.6) were selected using proportional stratified then simple random sampling technique. Besides, all (facilitators, Zone and Woreda Technical Committee) were included by purposive sampling techniques). Qualitative data was analyzed through narration and presented thematically. Whereas quantitative data was analyzed using (SPSS) version 19. The findings revealed that: there are problems of organization and management of Functional Adult literacy Program offered in Functional Adult literacy centers, Lack of resources, and qualified facilitatorsrs, unwillingness of stakeholders' participation on planning and implementation were some of the problems. Thus, these problems made organization and management of Functional Adult literacy Program to be incapable of meeting their purposes and the interests of disadvantages adult's learners. It is, therefore, recommended that the Oromia Education office, Zone and Woreda Adult Education Board and Technical Committee members and concerned sectors should make maximum possible efforts to mobilize resources, stakeholders and institutions under them to reverse the problems of Functional Adult literacy Program that offered in Functional Adult literacy centers.
\end{abstract}

Keywords: organization ; management ; functional adult literacy

DOI: $10.7176 / \mathrm{NMMC} / 80-02$

Publication date:May $31^{\text {st }} 2019$

\section{Introduction}

Education is an essential condition for multidimensional development, (MOE, 2008). Such developmental aspect within a nation is highly conditioned by proper organization and management as well as successful implementation of the educational program at all level. However, the adult education program carried out in the past were inconsistent, uncoordinated and hence could not bring the required results. Therefore, As to $\mathrm{MoE}(2008)$. It is necessary to provide the sector with coordinated management through coordination of relevant organizational structure for the management of Adult Education that is responsible for policy formulation.

Organization and management of FALP will be more effective if it delegates most activities zonal, districts and to the local level, in favor of the active participation of the efforts of various providers. (Gboku, 2007:18; Bernd, 2005:443-436). proper organization of nonformal education and its management is becoming as a vital means of enabling the educational endeavors of nations to relate with the overall development plan.

According, to Muller, (1997:57 cited in Mulugeta (2002: 18) Any educational system either formal or nonformal education cannot achieve its maximum possible result unless it is properly organized, managed as well as equipped with necessary resources (human, materials and financial). stressed that There are different program areas of education. Out of nonformula education programs, Functional Adult Literacy program is one of the known government Agenda. (SMUC, (2006: 26)

St. Marry, (2006: 85), further asserted that, the role of Functional Adult Literacy (FAL) program is still increasingly very important issues in developed and developing nations. Besides, Bhola(1984:3) stressed that proper organized functional adult literacy program has advantages for an individual to be independent in his daily. Organization and management of FAL program need not only trainers but also it needs trainees and other stakeholders' participation (MOE, 1999:66). The government alone cannot meet the needs of all beneficiaries in the FAL program. Thus there is a considerable high expectation from these sections either individually or in groups starting from need assessment up to program implementation and evaluation. Moreover, the stakeholders 
can provide the necessary raw materials, financial support and involve themselves in practical activities like labor.

Different researchers conduct their study on adult nonformal education in a broad sense. For instance, the research result of MoE (1999) on the status of nonformal education in Ethiopia indicated as that, stakeholders participation on functional adult literacy program implementation are not sufficient unless the Functional adult Literacy centers are properly managed and organized to the need of the local communities. In addition, Debeli (2011). Confirmed that, women's participation is very less on Functional Adult Literacy program planning, implementation and evaluation. Although the researchers gave their own recommendation based on their finding, still the problem of organization and management FAL program is not solved in Oromia Regional State in general and in West Harerge Zone in particular.

Therefore, conducting the study on the target areas may solve the problem of Functional Adult Literacy Program implementation to the rest of Zone Woredas and assess the organization and management of Functional Adult Literacy Program (FALP) so as to indicate a crisis of serious maladjustment of organization and management of FAL program in the targeted area. Moreover, the information generated by this study will have multi-dimensional use and purposes. It will help to plan appropriate interventions.

Although huge investment of education made and many of the workshops released by the Government, various NGO \& Private sectors, the FAL centers to offer FAL program were unable to bring change in the actual life of the individuals.

Besides, most of the FALP which offered in centers were found to be ineffective and inefficient due to serious maladjustment of organization and management practice. Even though Engidayehu Tegene (2010:23) studied on FAL centers, still the problem of the organization and management of FAL program is not solved. Moreover, Engidayehu on his research process mainly focuses on FAL centers. According to Government FAL program, still, there is a coordinating gap among top-level administrative and different concerned sectors. Having the recommended idea of different researchers as a base, the researcher needs to investigate administrative bodies coordination from the top level to FALTCs trainers. Therefore, the purpose of this study is, to assess the organization and management of Functional Adult Literacy Program in some selected Woredas of West Harerge Zone of Oromia Regional State. To this end, the study attempted to have the following objectives

\section{Objective}

1 To assess the current status and practice of functional adult literacy program (in terms of, provision, management, and organization).

2 To identify the major factors affecting the organization and management of FAL program in selected woredas of West Harerge Zone of Oromia.

3 To identify the major contributions played by concerned government and NGOs in implementing of FAL.

\section{Methodology}

The main purpose of this study was to assess the Organization and Management of Functional Adult Literacy Program. To do this, the researcher employed a mixed research design. The main methodological concern of the research was a descriptive explanation of the responses for the given questionnaires, interview, observation and document review. As (Merriam, 1988, Best and Kahn, 2005, Victor, 2006) cited in Sisay Awgichew, (2017), these instruments help to capture viable information and analyze with triangulation. On top of this, Primary data was obtained from FALP trainees, Facilitators, Woreda technical committee, whereas, the secondary data were obtained from different documents review work plan letters, reports of FAL centers,

Out of 17 Woredas which found in West Harerghe Zone, 6(Chiro, Tullio, Gemecis, Miesso, Gubakoricha, Beddessa,) of them were selected by simple random sampling techniques with their respective FAL training centers such as, (Mendhicho, Hirna primary school, Gemechis Elementary school, Bordode, Kora, Bedesa No 1 elementary school) so as to give equal chance. With regard to sample subject; the study was included trainees, trainers/facilitators, Woredas and Zone Adult Education Technical Committee members.

The total population of trainees 121 trainees which found six centers 78 was selected respectively by proportional stratified simple random sampling techniques. Because these techniques help to keep the proportionality of participants in each Woreda of the training centers and give equal chances.

Each sampled FAE center has three facilitators from (education, Health, and Agriculture) sectors. Accordingly, all of them were selected by purposive sampling techniques. Because facilitators are more resourceful and expected to give full information about the FAL program which offered in FAL centers.

Even though there are seven technical committee members in each sampled Woreda, during study time, experts of (Education, Health and Agriculture) were functional and have full information about FAL in their respective Woreda. Therefore, out of 42 Woreda AETC members, which found under the six Woredas, 18(42\%) of them were purposefully selected. Because the three sectors are more documented and resourceful on the 
organization and management of FAL program that offered in FAL centers. Finally, all Zone AEBTC members $7(100 \%)$ were included by purposive sampling techniques. Because they took short term training and expected to give full information. Besides, they have similar background information about FALP that offered in FAL centers.

The following table summarizes the sample size and sampling techniques

Table 1 Sample size and sampling techniques

\begin{tabular}{|c|c|c|c|c|c|}
\hline No & Woredas & $\begin{array}{l}\text { Respondent } \\
\text { Groups }\end{array}$ & $\begin{array}{l}\text { Population } \\
\text { Size }\end{array}$ & $\begin{array}{l}\text { Sample } \\
\text { Size }\end{array}$ & $\begin{array}{l}\text { Sampling } \\
\text { Techniques }\end{array}$ \\
\hline 1 & Chiro (Mendicho) & Trainees & 19 & 12 & $\begin{array}{l}\mathrm{P} / \text { Stratified } \\
\text { sampling }\end{array}$ \\
\hline 2 & Tullo (Hirna P/school) & Trainees & 18 & 12 & $6 \%$ \\
\hline 3 & Gamachis(gem/P/school) & Trainees & 25 & 16 & “" \\
\hline 4 & Miesso (Bordede) & Trainees & 17 & 11 & \\
\hline 5 & Gubakoricha (Kora) & Trainees & 21 & 14 & “"” \\
\hline 6 & $\begin{array}{l}\text { Bethesda (No } 1 \text { Elementary } \\
\text { school) }\end{array}$ & Trainees & 21 & 14 & “" \\
\hline \multicolumn{2}{|c|}{ Total } & & 121 & $\begin{array}{c}78 \\
(64.5 \%) \\
\end{array}$ & \\
\hline & \multirow[t]{2}{*}{ Six Woredas } & Facilitators & 18 & $18(100)$ & $\begin{array}{l}\text { Purposive } \\
\text { sampling }\end{array}$ \\
\hline & & $\begin{array}{l}\text { Technical } \\
\text { Committee }\end{array}$ & 42 & $18(42.8)$ & $6 \%$ \\
\hline 7 & West $\mathrm{H} /$ Zone & $\begin{array}{l}\text { Technical } \\
\text { Committee }\end{array}$ & 7 & $7(100)$ & $6 "$ \\
\hline
\end{tabular}

\subsection{Instruments of Data Collection}

Two sets of Questionnaires were prepared to collect data from trainees, technical committee and facilitators. The first set for, technical committee and facilitators and the second set for FAL centers trainees. Following the preparation of trainees questionnaires, translation into Afan Oromo was done important. The content validity of the items in the questionnaire was examined by senior staff or colleagues and proved to be valid. The internal consistency reliability of the items in the questionnaire was determined in this study using Cronbach's alpha (r) and found to be 0.750 which is reliable. A semi-structured interview was employed to Zone Technical committee members. Besides, Observation and document reviews were done importantly.

The questionnaire was distributed to trainees and collected with the direct support of three data collectors. Because of the learners are unable to read and understand the questionnaires. At the same time, questionnaires were filled by center facilitators and Woreda technical committee.

\subsection{Data Analysis}

To analyze the quantitative data percentage and frequency, mean value, independent sample t-test and chi-square test were used by the help of SPSS of version 19. These statistical tests were used for the purpose of testing different variables between the respondent groups. In all case the difference obtained for statistical significant at alpha level $(\alpha)$ of 0.05 in two-tailed direction and the statistics books tables.

The qualitative data was narrated qualitatively using words, phrases, statements and paragraphs obtained from interviewees and open-ended questions. Hence the qualitative data was used as the complement of quantitative data. In the procedure of analysis of the study, each item was valuing to Krishnaswami and Ranganatham(2007)in Bultosa Hirko(2010) discussed that the most popular scale using this approaches is Likert scale of summated rating which was produced by person's name called Reinis Likert. In these cases where the Likert scale was applied, the mean values for each statement have value 1,2,3,4 and 5 represent ( Very High, High, Medium, Low and Very Low) respectively.

For analysis purpose, the respondents' responses were rated as 1.49 and below (very low), 1.50-2.49 (Low), 2.50-3.49 (Medium), 3.50-4.49 (High) and 4.50 and above (Very high) in order to identify the range between in each level. Therefore, the mean value below 2.50 was taken as weak(threats) and above 2.50 were the strength(opportunities). Moreover, the mean values were also used for further statistical analysis for significant differences of opinions among different groups.

\section{Results and Discussions}

A total of 114 copies of questionnaires were distributed to 78 trainees and 36 (Facilitators and Woreda Technical Committee). However, out of these, 67(85.9\%) trainees $16(88.9 \%)$ facilitators and $16(88.9 \%)$ Technical 
committee members, were appropriately filled and returned. Interviews were conducted with 7(100\%) Technical committee members and their responses were triangulated with qualitative data. Observation checklist and document analysis were also used in this study to complement the above instrument. Finally, the information collected from these questionnaires were presented and analyzed as follows.

\subsection{Respondents Background}

Female trainees $(44.8 \%)$ were proportional to male (55.2\%). However female facilitators account only $(20.5 \%)$. whereas male (79.55) Therefore, females participation was very low when compared with male participants both as a committee member and as facilitators. As reported on the below (Table 2), 35.8\% of the trainees were unable to read and write and the majorities (64.2\%) were also found under 1-4 grade level. Therefore, teaching/training needs a multi-grade system. Samuel, (2005:225) further stated that teaching adults in combined grade classrooms can be intimidating.

Table 2 Distribution of Respondents background information.

\begin{tabular}{|c|c|c|c|c|c|c|c|c|c|c|c|}
\hline \multirow{2}{*}{\multicolumn{2}{|c|}{ Back Ground information }} & \multicolumn{10}{|c|}{\begin{tabular}{|c|} 
Respondent Groups \\
\end{tabular}} \\
\hline & & \multicolumn{2}{|c|}{ Trainees } & \multicolumn{2}{|c|}{ facilitators } & \multicolumn{2}{|c|}{$\begin{array}{l}\text { Woreda } \\
\text { AETC }\end{array}$} & \multicolumn{2}{|c|}{$\begin{array}{l}\text { Zone } \\
\text { AETC }\end{array}$} & \multicolumn{2}{|c|}{ total } \\
\hline \multirow[t]{4}{*}{ Sex } & & $\mathrm{f}$ & $\%$ & $\mathrm{f}$ & $\%$ & $\mathrm{f}$ & $\%$ & $\mathrm{f}$ & $\%$ & $\mathrm{f}$ & $\%$ \\
\hline & $\mathrm{M}$ & 37 & 55.2 & 14 & 8.57 & 11 & 68.7 & 6 & 85.7 & 68 & 64.2 \\
\hline & $\mathrm{F}$ & 30 & 44.8 & 2 & 12.5 & 5 & 31.3 & 1 & 14.3 & 38 & 35.8 \\
\hline & $\mathrm{T}$ & 67 & 100 & 16 & & 16 & 100 & 7 & & 106 & 100 \\
\hline \multirow[t]{3}{*}{ Age } & $<20$ & 5 & 7.5 & & & & & & & 5 & 4.7 \\
\hline & $21-50$ & 60 & 29.9 & 16 & 37.5 & 10 & 62.5 & 5 & & 91 & 85.8 \\
\hline & $>51$ & 2 & 2.9 & & & 6 & 37.5 & 2 & & 10 & 9.4 \\
\hline \multirow[t]{5}{*}{$\begin{array}{l}\text { Educational } \\
\text { level }\end{array}$} & $\begin{array}{l}\text { Unable to read and } \\
\text { write }\end{array}$ & 24 & 35,8 & & & & & & & 24 & 22.6 \\
\hline & Grade 1-4 & 43 & 64.2 & & & & & & & 43 & 40.6 \\
\hline & Grade 5-10 & & & 4 & 25 & & & & & 4 & 3.8 \\
\hline & Diploma & & & 4 & 25 & 10 & 62.5 & & & 14 & 13.2 \\
\hline & B.A/B.Sc \& above & & & & & 6 & 37.5 & 7 & 100 & 13 & 12.3 \\
\hline \multirow[t]{3}{*}{ Field of study } & Teaching & & & 12 & 75.0 & 8 & 50.0 & 4 & 57.4 & 24 & 61.5 \\
\hline & Agriculture & & & 4 & 25.0 & 5 & 31.25 & 2 & 28.6 & 11 & 28.2 \\
\hline & Health & & & & & 3 & 18.75 & 1 & 14.3 & 4 & 10.3 \\
\hline
\end{tabular}

On the same table, $50.0 \%$ of the facilitators' complete Teachers Training Institute level. the majorities $62.5 \%$ of Woreda committee educational level were Diploma. Whereas $37.5 \%$ of them were degree holders. All $7(100 \%)$ of Zone technical committee were qualified with a degree.

Besides, majorities $12(75.0 \%)$ of the facilitators, 8(50.0\%) of Woreda AETC members and 4(57.2\%) of Zone AEBTC respondents were qualified in the teaching profession. Whereas $4(25 \%)$ of facilitators, $5(31.3 \%)$ Woreda AETC and 2(12.5\%) of Zone AEBTC members were also qualified from Agriculture and only 3(18.8\%) of Woreda AETC and 1(14.3\%) of Zone AEBTC members were from Health. This indicates that, in West Harerghe Zone, there were no respondents who qualified with a nonformal education program to run the FAL program.

\subsection{The Current Status and practice of FAL Program in terms of: a. FAL program provisions}

As indicated on item " 1 " the majorities $8(50.0 \%)$ of facilitators have medium interest. Whereas, $6(37.5 \%)$ of facilitator were not interested to give training in FAL centers.

On the same table, the majorities $13(81.5 \%)$ of the Woreda Technical committee also interested to work as a committee member.. Although the majorities 21(65.6\%) of the two respondent groups have medium working interest on their current position, The chi-square test shows that there was a statistically different relationship on working interest between the two groups with the value at $\mathrm{p}$-value is less than the significant alpha 0.05.

This implies that facilitatorare were less interested than Woreda Technical Committee. This result is similar with the research findings of (Debeli, 2011). From his research finding, it is observed that facilitators need the incentive to help trainees. According to the majorities of $23(71.9 \%)$ of facilitators and Woreda committee, training given for workers was not enough. Besides, the information gathered confirmed that, those who received continuous training were not satisfied. So, they need additional training. and this implies that it is no difference between two groups in relation to on the job training. On item 3 below, the majorities $8(25.0 \%)$ of the trainers were strongly disagreed on Woreda activities of training material provisions. On the contrary, 6(37.5\%) of Woreda AETC were strongly agree on Woreda activities of training material provisions to FAL centers. This 
reveals that there is a contradiction between trainers and Woreda AETC respondents.

There was also a significantly different idea on the responses of two respondent groups with regard to Woreda training material provision at $\mathrm{p}<0.05$. The observation checklist showed that Woreda activities of training material provisions are less. Most teaching materials were found in the store.

No trainers are purposefully assigned for FAL training. Those who assigned from different sectors needs incentive since they believe that FALP which offered in FAL centers are additional work to their regular occupation. But still, there is no incentive to motivate them

Table 3 Working Interest and Activities on Program Provision.

\begin{tabular}{|c|c|c|c|c|c|c|c|c|c|c|c|}
\hline \multirow{3}{*}{ No } & \multirow{3}{*}{ Activities (Items) } & \multirow{3}{*}{ responses } & \multicolumn{6}{|c|}{ Respondent Groups } & \multicolumn{3}{|c|}{$\mathbf{X}^{2}$} \\
\hline & & & \multicolumn{2}{|c|}{ Trainers } & \multicolumn{2}{|c|}{ WAEBTC } & \multicolumn{2}{|c|}{ Total } & \multirow[t]{2}{*}{ cv } & \multirow[t]{2}{*}{ df } & \multirow[t]{2}{*}{ p-value } \\
\hline & & & $\mathbf{f}$ & $\%$ & $\mathbf{f}$ & $\%$ & $\mathbf{f}$ & $\%$ & & & \\
\hline \multirow[t]{4}{*}{1} & \multirow{4}{*}{$\begin{array}{l}\text { Workers interests to } \\
\text { work on their current } \\
\text { position }\end{array}$} & $\mathrm{H}$ & 2 & 12.5 & 3 & 18.8 & 5 & 15.6 & \multirow[t]{4}{*}{7.390} & \multirow[t]{4}{*}{2} & \multirow[t]{4}{*}{.025} \\
\hline & & $\mathrm{M}$ & 8 & 50.0 & 13 & 81.5 & 21 & 65.6 & & & \\
\hline & & $\mathrm{L}$ & 6 & 35.5 & - & - & 6 & 18.8 & & & \\
\hline & & No & 7 & 43.75 & 3 & 18.75 & 10 & 31.25 & & & \\
\hline \multirow[t]{2}{*}{2} & \multirow{2}{*}{$\begin{array}{l}\text { Adequacy of training } \\
\text { to Workers }\end{array}$} & Not Enough & 10 & 62.5 & 13 & 81.25 & 23 & 71.9 & \multirow[t]{2}{*}{1.391} & \multirow[t]{2}{*}{1} & \multirow[t]{2}{*}{.238} \\
\hline & & No response & 6 & 7.5 & 3 & 18.7 & 9 & 28.1 & & & \\
\hline \multirow[t]{4}{*}{3} & \multirow{4}{*}{$\begin{array}{l}\text { AETC participated in } \\
\text { training material } \\
\text { provisions }\end{array}$} & SA & 0 & 0 & 6 & 37.5 & 6 & 18.8 & \multirow{4}{*}{18.39} & \multirow{4}{*}{3} & \multirow{4}{*}{.000} \\
\hline & & $\mathrm{A}$ & 1 & 3.1 & 6 & 37.5 & 7 & 21.9 & & & \\
\hline & & DS & 7 & 21.9 & 4 & 125 & 11 & 34.4 & & & \\
\hline & & SD & 8 & 25.0 & 0 & $.0 \%$ & 8 & 25 & & & \\
\hline
\end{tabular}

\section{b. FAL program management and organization}

As illustrated on items "1", " 2 ", and " 3 " of table 4, the total mean value of the responses of the two respondent groups were $1,59,1.69$, and 2.05 respectively. These average mean values indicate that organizational effectiveness and structure of FAL centers recourse management abilities, need assessment activities to run FALP in FAL centers were low. Because the average mean value for the above items was range from 1.50- 2.49.

According to data obtained from the interview and document analysis, revealed that, "there is no good organized structure regarding FAL program. As a result, in most FAL centers, there was a lack of resource management abilities. In addition, the researcher observes that there are activities of need assessment before training in FAL centers. However, the extent of need assessment before training was varying from centers to centers in West Harerghe Zone.

Regarding item 4, the average mean value of facilitators and WAEBTC members on the level of trainees encouragement was (3.59) which is "High" and the average mean value of trainees was (2.24) which is "low". This implies that trainees' encouragement was "low". The two respondent group's responses were contradicted on the issue of trainees' encouragement in FAL centers.

This reveals that facilitators and WAEBTC members did not clearly understand the interest of trainees. They might deny giving clear information on the level of trainees' encouragement in FAL center

Table 4, Current Organization and Management Practices of FAL Centers

\begin{tabular}{|c|c|c|c|c|c|c|c|}
\hline \multirow[t]{3}{*}{ No } & \multirow[t]{3}{*}{ items } & \multicolumn{2}{|c|}{ Respondents rating scale } & \multirow{3}{*}{$\mathrm{x}$} & \multirow{3}{*}{ sd } & \multicolumn{2}{|c|}{ t-test } \\
\hline & & \multirow{2}{*}{$\begin{array}{c}\text { Trainees } \\
\text { Mean } \\
\end{array}$} & \multirow{2}{*}{$\begin{array}{l}\text { Trainers \& } \\
\text { Woreda AETC } \\
\text { Mean }\end{array}$} & & & \multirow{2}{*}{$\mathrm{cV}$} & \multirow{2}{*}{$\mathrm{P}$-value } \\
\hline & & & & & & & \\
\hline 1 & $\begin{array}{l}\text { Level of FALCs organizational } \\
\text { structure }\end{array}$ & 1.60 & 1.56 & 1.59 & .796 & .201 & .841 \\
\hline 2 & $\begin{array}{l}\text { Resource management ability in } \\
\text { the FAL center }\end{array}$ & 1.63 & 1.81 & 1.69 & .829 & -1.043 & .300 \\
\hline 3 & $\begin{array}{l}\text { The activity of need assessment } \\
\text { before training }\end{array}$ & 1.78 & 2.63 & 2.05 & 1.044 & -3.581 & .001 \\
\hline
\end{tabular}

The mean score obtained from the data were interpreted as 0.05-1.49(very low), 1.50-2.49(low), 2.503.49(medium), 3.50-4.49(high) and above 4.50(very high) and Where VH = Very High, H = High, M- Medium, L- Low and VL $=$ Very Low

\subsection{Factors affecting the organization and management of FAL program}

As illustrated in item 1 of table 5 above, the responses of the sample groups of trainees, facilitators, and Woreda AETC show that there is lack of household labor to participate in FALP training since the grand mean values for two items (GM range from 3.54 to 3.90) indicate sample groups agreement. One way ANOVA test also show that there are significantly different at $\mathrm{p}=.000<0.05$. 
As reported on the same table of item 2 bellow, facilitators lack sufficient experience to run FALP in FAL centers $(\mathrm{GM}=4.51)$. This value indicates strongly agree. This revealed that most trainees strongly agree on facilitators' lack of sufficient experience. Similarly, facilitators themselves and WAEBTC also agree on facilitators' lack of sufficient experience to give work-based training in FAL centers. Thus, the training given to facilitators might not fill the skill gap so as to help trainees.

As indicated in item 3 below, the average mean value of group respondents was (1.92). This revealed their degree of disagreement. Post hoc comparisons using the Tukey HSD test indicated that the mean score of facilitators $(\mathrm{M}=1.13)$ is significantly different than the mean scores of trainees (2.21) and Woreda AETC (1.50). However, there are no meaningful differences between trainees and Woreda AEBTC respondents.

This revealed that facilitators are not commuted to provide the necessary skill and knowledge to trainees. According to the obtained result and information gathered from open-ended questions, it is approved that, there are trainees who fear for their religions to attend FALP in FAL centers Therefore, AETC members; different concerned ministries, Woredas, and Zone administrative bodies might not have a purposeful culture of discussion with local communities regarding the uses of FALP.

Table 5 Socio-Economic, Human Resource and Social Resistance affecting implementation

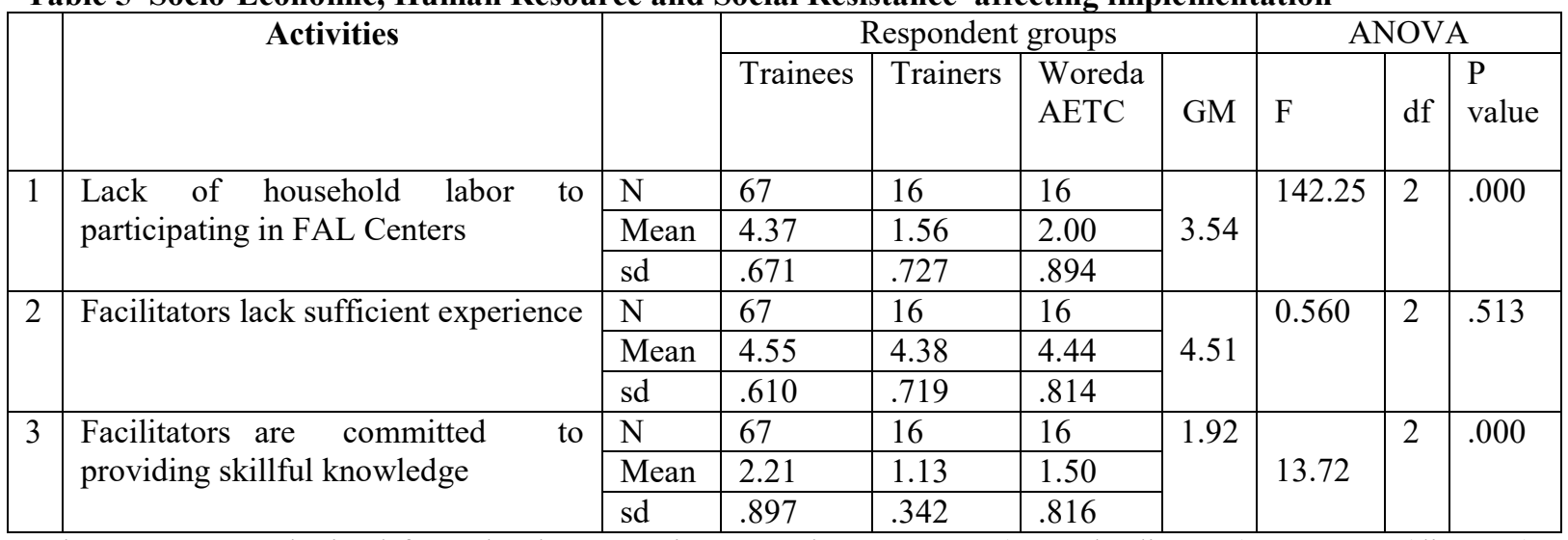

a. The mean score obtained from the data were interpreted as 0.05-1.49(strongly disagree), 1.50-2.49(disagree), 2.50-3.49(undecided), 3.50-4.49(agree) and above 4.50(strongly agree) Where $\mathrm{M}=$ mean, $\mathrm{a}=$ standard deviation and $\mathrm{GM}=$ Grand Mean

\subsection{Government, and NGOs contributions on implementing of FAL.}

On table 6 below, the mean value of two respondent groups for item 1, and 2 were range from (1.53-2.49), low. This indicates that in West Harerghe Zone government bodies contribution on capacity building and the Extent of facilitators encouragement were found to be low. The report obtained from these items were contradicting with the research result of Engidayeh(2010). According to his finding, government contribution to trainers/facilitator encouragement was high in Amahara Regional State.

The $t$ test also show that, there were no statistically any significant different at $\mathrm{p}>0.05$ and the calculated $\mathrm{t}$ value $(\mathrm{cv}=2.40, \mathrm{p}=0.108$ for item 1 , and $\mathrm{cv}=1.957, \mathrm{p}=0.053$ for item 2$)$.

On table 6 of items 4and 5 Respondents were asked to level NGOs contribution in budget allocation and involvement in supporting the training program in FAL centers.

Accordingly, the average means value of both items (range from 1.18-1.32) which is very low. This reveals that NGOs contribution in allocating budget and logistic and its level of involvement in supporting the training program in FAL centers was very low in West Harerghe Zone.

The reviewed literature (MOE, 1999) indicate that, in Ethiopia, in the most pastoral area of Oromia and other regions, NGOs support the FAL centers in organizing and sponsoring workshops. In addition, according to (Anthoney, 2006), Action Aid participate in 40 countries with allocating budget and logistics for FAL program implementation. Therefore the results obtained from respondent report contradict with their review literature. This variation might be rising due to lack of NGOs site on the area.

As reported in table 6, The mean averages of trainees for items 6 and 7, respectively 3.27 and 1.96. Whereas, the mean average of facilitators and WAEBTC respondent for the same items were respectively 2.23 and 1.84. There was a significant difference between the mean average of trainees' and a mean average of facilitators and WAEBTC respondents. The trainees' respondents for items 6 an 7 were respectively "medium and low" and the trainers and WAEBTC respondents for the same items were low. This implies that for the trainees' respondents, positive attitude towards FALP in FAL centers is medium, On the contrary, trainers and WAEBTC respondents have a negative attitude towards FALP in FAL centers.

This reveals that in West Harerghe Zone, Trainees encouragement and involvement to strengthening the 
capacity of FAL centers and giving comment on the lesson provided were low. This might be due to the low commitment of facilitators to aware of the community. Therefore; it needs amendment and further improvement.

Table 6 Government and NGOs Contribution to FAL program Implementation

\begin{tabular}{|c|c|c|c|c|c|c|c|}
\hline & & \multicolumn{2}{|c|}{ Respondents rating scale } & \multirow{3}{*}{$\mathrm{x}$} & \multirow{3}{*}{ sd } & \multirow{3}{*}{$\begin{array}{c}\text { t-test } \\
\mathrm{cv}\end{array}$} & \multirow{3}{*}{$\begin{array}{l}\mathrm{P} \\
\text { value }\end{array}$} \\
\hline & & Trainees & $\begin{array}{l}\text { Trainers } \& \\
\text { Woreda AETC }\end{array}$ & & & & \\
\hline & & $\mathrm{M}$ & $\mathrm{M}$ & & & & \\
\hline 1 & Level of the capacity building & 2.3 & 2.39 & 2.49 & 1.207 & $-\overline{2} \cdot 400$ & .108 \\
\hline 2 & The extent of facilitators encouragement & 1.39 & 1.81 & 1.53 & 1.024 & $\begin{array}{l}- \\
1.957\end{array}$ & .053 \\
\hline 4 & budget and logistic allocation to run FALP & 1.38 & 1.19 & 1.18 & .502 & -077 & .939 \\
\hline 5 & NGOs Involvement to support FAL centers & 1.39 & 1.19 & 1.32 & .603 & 1.856 & .122 \\
\hline 6 & Attitude towards FALP in FAL centers & 3.27 & 2.23 & 2.96 & 1.039 & 4.094 & .000 \\
\hline 7 & $\begin{array}{l}\text { Trainees involvement in strengthening the } \\
\text { capacity of FAL centers }\end{array}$ & 1.96 & 1.84 & 1.92 & .877 & .533 & .596 \\
\hline
\end{tabular}

Significance difference if $\mathrm{p}<0.05$ (2-tailed) or the calculated value (cv) is greater than critical/table value. The calculated/table value is 6.314 for $\mathrm{df}=12.920$ for $\mathrm{df}=2$

\section{Conclusions}

The following conclusions were drowning.

1. From the finding it is concluded that females' participation was very low when compared with male participants both as a committee member and as facilitators. Therefore, teaching/training those different education levels may need a great effort. From the finding also it is concluded that, facilitators' complete Teachers Training Institute. Woreda and Zone technical committee educational level were respectively found to be Diploma and. Degree.

2. Regarding the respondents' field of study, there were no respondents who qualified with a non-formal education program. It is also concluded that at the beginning of FALP training, most trainers and Woreda Technical committee were very interested to work on their current position. However, two years later, particularly facilitators' interest becoming decreases from time to time due to overlapping program and lack of incentive on the areas. Most Facilitators prefer to teach their regular class. This result is similar to (Debeli, 2011). From his research finding, it is observed that facilitators need the incentive to help trainees. They need more help from the government and Non-government. Therefore, in order to change the attitude of facilitators, continuous area related training and more awareness creation program should be needed

3. With regards to training given, trainers who received the training described on their open-ended questions that, the training was not enough to perform the role of facilitating and working as a committee member effectively. They need additional training in relation to their current position. Most teaching materials were found in the store, facilitators were recruited from formal school teachers, No trainers directly assigned for FAL centers. It is further concluded that, there are activities of need assessment before training in FAL centers. However, the extent of need assessment before training was varying from centers to centers.

4. Woreda Technical committee did not clearly understand the interest of trainees. There is a lack of household labor to participate in FALP training. Facilitators' also have a lack of experience to deliver work-based training in FAL centers. Training given to facilitators might not fill the skill gap. Facilitators are not commuted to provide the necessary skill and knowledge to trainees..

5. There is NGOs contribution in allocating budget and logistic. According to (MOE, 1999) and (Anthoney, 2006), Ngo like Action Aid played a great role in allocating budget and logistics for FAL program implementation. However, the results obtained from the respondent, contradict this idea. This variation might be rising due to the absences of NGOs site on the area.

\section{Recommendation}

1. The participation of governmental organization, NGOs, local communities' private sectors should be strengthened in such a way that the community developed a culture of discussion, sense of ownership of FAL centers and its programs. It is also recommended that Zone and woreda administrative, Zone and woreda AEBTC, facilitators and Kebele concerned bodies private sectors and the nearby communities have to evaluate themselves regarding FALP implementation.

2. In addition, Zone and woreda administrative, technical committee, facilitators and Kebele concerned bodies private sectors have to shared experiences from other Zones' and Regions' so as to know where they are and 
so as to work hard to achieve the intended objectives of FAL centers.

3. Finally, as this study was limited in some respects, the researcher would like to call upon everybody, who has the resources and the capabilities, to further carry out in-depth investigations to come up with more valid and/or comprehensive findings.

References

Anthony, O.(2006:) Continuation and Extension of Literacy Programs: from Literacy to Adult Basic Education and Beyond in Uganda: Association for the Development of Education in Africa (ADEA)

Bernd, (2005:443-436). Adult Literacy Lessons and Promises: A Mozambican Literacy campaigns 1978-1982, Institute of International Education, University of Stockholm, (PH.D. Dissertation).

Bhola, H.S (1995). Functional Literacy, Workplace literacy, and Technical and Vocational Education: Interface and Policy Perspective. UNESCO, Paris. ED- 95/WS-29

Bultosa Hirko, (2010) The Practice and Problems of TVET Reform Implementation West Harerghe Zone of Oromia Region: Addis Ababa. M.A Thesis (unpublished).

Dabali Hundessa, (2011). Factors Affecting the Participation of Women in Functional Adult Literacy Program In Menesibu and Nejo Woredas of West Wollega Zone of Oromia Region Unpublished MA Thesis: AAU

Engidayehu Tegene (2010) Organization and Management of Nonformal Skill Training Program in South Gonder Administrative Zone. Unpublished MA Thesis: AAU. Ethiopia. Ourael Printing Press: Addis Ababa.

Gboku, (2007:18;) Developing Programs for Adult Learners in Africa: African perspective on Adult Learning. IIZ/DVV. Botswana: Rolene Liebenberg.

MOE/ICDR (1999). A Study on the Status of Non-Formal Education in Some Regions of the country: Addis Ababa Ethiopia.

MOE, (2008). National Adult Literacy Curriculum Framework, Action Plan and benchmarks. AddisAbaba

Mulugeta Menkir (2002) The Implementation Of Adult Literacy Program In East Gojjam Zone (Amhara Region). Unpublished thesis: AAU

Sisay Awgichew, (2017), Integrated Functional Adult Literacy: Existing Practices and Challenges in Eastern Ethiopia: international Journal of Education \& Literacy Studies ISSN: 2202-9478 www.ijels.aiac.org.au

SMUC, (2006: 26) Provision and participants of adult education: An overview. In the proceeding of the symposium on adult education and development, pp.196-210. (Goethe Institute, Geberekirstos Desta Center, Addis Ababa, Ethiopia).

St. Marry University College (2006). Management of Adult and Nonformal Education. Addis Ababa: Ethiopia (Edpm 204). 